\title{
What Leaders Should Know about E-Government
}

\author{
Raphael Louis \\ H.E. Hon. Sir. Dr., Leader-President/CEO, Lt. General (OSP), FAAVM, NCPC, OSP; Ontario, Canada
}

\begin{abstract}
Globalisation and the advancement of Information Communication Technology (ICT) have changed the world that we live in. Because of this phenomenon, this has forced governments around the world to change in becoming more active in the deployment of digital services to its citizens and businesses. The success of fully implementing e-government requires a careful adoption and full understanding of the technology that is being applied. Adding that, it is about transforming the whole government into a complete entity where citizens and businesses seamlessly interact with government services on line. However, despite the wide use of ICT, research on e-government suggests that it has not yet reached its full potential of integration.
\end{abstract}

Keywords: e-government, leadership, organizational transformation, cyber security.

JEL Classification: H1, L86, G38.

(C) The Author, 2017. This article is published with open access at ARMG Publishing.

\section{Introduction}

The drive towards a digital society in the global economy has caused many governments to rethink their position and their role for development. This study suggests that a new style of leadership which has certain characteristics is required to advance the agenda of e-government, and reach the highest level of maturity. Providing a presence on the World Wide Web (WWW) is not enough and gives a limit to the whole objective of e-government. Therefore, those leaders who posses the quality of innovators and early adopters would be able to move successfully into the last stage of the e-government maturity model and the importance of understanding of the technology lifecycle, and how government leaders play an important role alongside technology in making a complete transformation of e-government.

The UN E-Government Survey 2016 on "E-Government in Support of Sustainable Development" offers a snapshot of trends in the development of e-government in countries across the globe. According to the Survey more governments are embracing information and communication technologies (ICTs) to deliver services and to engage people in decision-making processes in all regions of the world. The 2016 UN EGovernment Survey provides new evidence that e-government has the potential to help support the implementation of the 2030 Agenda and its 17 sustainable development goals (SDGs). The Survey indicates a positive global trend towards higher levels of e-government development as countries in all regions are increasingly embracing innovation and utilizing new ICTs to deliver services and engage people in decisionmaking processes. It underscores that one of the most important new trends is the advancement of peopledriven services - services that reflect people's needs and are driven by them. At the same time, disparities remain within and among countries. Lack of access to technology, poverty and inequality prevent people from fully taking advantage of the potential of ICTs and e-government for sustainable development.

\section{Definition of leadership}

Leadership, as it is commonly understood, focuses on the accomplishment of the mission and goals of organisations. The performance of leaders of organisations is measured by the delivery of products and services to meet the needs of its customers. Boundaries or borders matter because they outline authority, power, responsibility, funding, and mission of an organisation. Successful leaders of organisations have well developed 'vertical muscles' but leaders who assume responsibility for cross-boundary change initiatives need to exercise 'horizontal muscles' (Price Waterhouse Change Integration Team, 1995), cited in (McDaniel, 2005).

\section{Why leadership is important in e-government?}

Strong leadership can speed up the process of e-government implementation, promote co-ordination within and among agencies and help reinforce good governance objectives and best practices. Strong leadership can tackle the big challenges of e-government and assume professional risks and exercise skills in cross- 
boundary leadership, while creating from their experiences a set of promising goals, objectives, practices, and policies for future generations of e-government leaders. Strong leaders always keep their eyes on their organisation's mission, vision, and goals, manage the attitude and commitments of senior leaders of their own organisations, and select concrete evidence of the impact of inter-governmental activities and projects that can be communicated easily, quickly, and powerfully to justify participation beyond their individual organisation's boundaries and resources.

\section{Integrated services and policies through e-government}

A new trend in e-government is the evolution towards integrated public services online through one-stop platforms. Services from various public agencies are bundled together as a single, joined-up service in a one-stop-shop. This makes it easier for people to interact with public administration. According to the United Nations (UN) 2016 Survey: 90 countries (including over 50 developing countries) provide a link to a one-stop-shop service platform; 105 countries provide advanced search features; 98 countries require digital ID for online or mobile services; and 71 countries provide an online tracking system.

E-government can help connect individual systems and government functions, as well as public services, into a coherent system, thus enabling whole-of-government (WoG) service delivery in the economic, social, and environmental areas. Governments should aim to deliver integrated services, not only between economic, social, and environmental areas but also between various sectors, subsectors and activities.

E-government will inevitably help siloed governments integrate. The automated systems used in egovernment inherently require a certain level of standardisation, convergence, and interconnectivity in order to work. This technological integration may then carry over into better institutional connectedness and integration. Trends show an increasing number of countries with a government-wide CIO institution or equivalent authority body for coordinating national e-government development.

E-government serves as an enabler of policy integration. It provides governments with increased insight into complex issues and analysis of a situation or policy, and offers opportunities to re-engineer existing decision-making processes and information flows. However, policy integration presents a major challenge for many countries. Formulating integrated policies requires deep insight into a range of complex issues across economic, social, and environmental dimensions.

\section{Open Government Data for promoting transparent institutions}

To make public institutions more inclusive, effective, accountable and transparent, many governments are opening up their data for public information and scrutiny. Making data available online for free allows the public and various civil society organizations to reuse and remix them for any purpose. This can potentially lead to innovation and new or improved services, new understanding, and new ideas. Overall, in 2016, 128 out of 193 UN Member States provide datasets on government spending in machine readable formats. The use of open government data varies around the world in terms of the number of datasets released, how they are presented, and in the tools provided to increase usage of data.

Combining open data with new technologies like Big Data analytics, the Internet of Things, geographic information systems are powerful tools for efficiency gains and anticipatory governance, to focus on prevention rather than reaction. The issue that many governments are tackling today is not whether to open their data, but how to do so. Challenges include issues related to legal frameworks, policies and principles, data management and protection, identity management and privacy, as well as cyber security. A governmentwide vision, collaborative leadership, adequate human resources, appropriate legislation, and institutional frameworks as well as clear data governance are essential to open up government data.

Strategies such as capacity building programmes, tutorials, Open Government Data guidance tool-kits, data dictionaries, app competitions and data literacy campaigns are essential to empower people to use government data. These tools should be employed to reach out to all people in society, including vulnerable groups. Ensuring access to the Internet and bridging the digital divides is critical.

\section{E-participation to promote participatory decision-making}

E-participation is expanding all over the world. With growing access to social media, an increasing number of countries now proactively use networking opportunities to engage with people and evolve towards participatory decision-making. This is done through open data, online consultations, and multiple ICT-related 
channels. While developed countries, especially European countries, are among the top 50 performers, many developing countries are making good progress as well. Lower income levels do not hamper posting basic public-sector information online and using social networking for engaging with people on a broad range of development-related issues.

A growing number of e-participation applications and tools are put in place in various sectors with the objective of responding to the needs of various communities. This can contribute to the development of new forms of collaborative partnerships between government bodies and people and reinforces the focus on people's needs. E-participation highly depends on strong political commitment, collaborative leadership, vision, and appropriate institutional frameworks that ensure structured ways of engaging people. E-participation also requires capacity development and training programmes for government leaders, public officials and for civil society, including digital literacy for vulnerable groups.

\section{Advanced online services and bridging divides}

Countries across the world have made substantial progress in online service delivery. Higher levels of online service tend to be positively correlated with a country's income level. The survey shows that digital technologies the Internet, mobile phones, and all the other tools to collect, store, analyze, and share information digitally are being increasingly utilized.

Governments are increasingly adapting e-government services for the mobile platform, providing public sector field workers access to mobile applications, enabling smart/flexible working, and delivering citizen services anytime, anywhere. In all sectors reviewed, mobile apps and SMS services have experienced a large and significant growth. Accessibility and availability of mobile devices support improvements in health, education, agriculture, commerce, finance, and social welfare. It can allow regions that leapfrogged into wireless broadband to step up innovation and narrow the digital divide. Overall, ensuring the accessibility and availability of broadband remains an urgent global priority.

The use of Geographic Information System data and Internet of Things (IoT) hold the potential to transform the way public policy is formulated, implemented, and monitored. Their early adoption has shown increased levels of civic participation and enhanced efficiency, transparency, and accountability of public institutions. However, improvements of legal and regulatory frameworks and enhanced cooperation are required at all levels. Bridging the digital divide between countries and people is a key objective of the international community. It requires international cooperation and support. It also requires mobilizing the public and private sectors and societies at large to develop the kind of devices, applications, technologies, and safeguards that can enable and mobilize ICT for addressing poverty, illiteracy, and disease. Progress has to be accompanied by policies to equip people to use online and mobile services, and develop the necessary enabling environment and safeguards.

\section{Billions of people in developing world still without Internet access UN report finds}

Broadband Internet is failing to reach billions of people living in the developing world, including 90 per cent of those living in the poorest nations, according to a new United Nations report that offers country-bycountry data on the state of access around the globe. The State of Broadband, produced by the UN Broadband Commission, reveals that 57 per cent of the world's people remain offline and unable to take advantage of the enormous economic and social benefits the Internet can offer. Although most developing countries have still basic problems such as education, poverty, housing, and health, which are sure priorities for any government, it is important to determine whether an advanced informational infrastructure provides critical economic advantages as a tool for economic leapfrogging and social development. If that is the actual case, then early investments in the provision of that infrastructure can potentially bring fast and radical changes in the future of the nation's economy.

While the challenges faced by each developing country are largely determined by its local cultural, political, and economic conditions, we found common themes in the countries' successful development strategies. For instance, most of the strategies that have successfully combated the lack of rural communications infrastructure involve some form of public, community-based internet access rather than individual internet access. Likewise, none of the countries benefited from government monopolization of the Internet development process, largely because Internet protocols had been standardized by developed nations. Finally, foreign investment played a large part in successful technological ventures. 


\section{Cybercrime, cybersecurity, and cyberterrorism}

The advances in information technologies and modern society's dependence on digital infrastructure have generated new threats and challenges to be addressed. Cyber warfare, terrorist use of the internet, cyber espionage, online crimes against property and persons embody growing transnational menaces to civil society in a hyper-connected world. Conversely, governments' responses to counter cyber threats and to safeguard national security through the internet are triggering an ethical debate: are security measures putting freedom of expression in danger? With advancements in technology and wider accessibility to the Internet, the global community is now faced with a new platform in which criminal activity can take place. Cyber criminals are attacking societies and economies targeting governments through their vital services, like critical infrastructures (transportation, water supply, hospitals), and companies, big multinationals as well as small medium enterprises.

\section{A Definition of cyber security}

Cybersecurity refers to the preventative techniques used to protect the integrity of networks, programs and data from attack, damage, or unauthorized access. Cybersecurity involves protecting information and systems from major cyberthreats, such as cyber terrorism, cyber warfare, and cyber espionage. In their most disruptive form, cyberthreats take aim at secret, political, military, or infrastructural assets of a nation, or its people. Cybersecurity is therefore a critical part of any governments' security strategy. The U.S. federal government for example, has allotted over $\$ 13$ billion annually to cybersecurity since late 2010 .

\section{Cyber terrorism}

Cyber terrorism is the disruptive use of information technology by terrorist groups to further their ideological or political agenda. This takes the form of attacks on networks, computer systems, and telecommunication infrastructures. For example, in response to the removal of a Russian WWII memorial in 2007, Estonia was hit with a massive distributed denial of service (DDoS) attack that knocked almost all ministry networks and two major bank networks offline. The rise in such cyber terrorism attacks is measurable: in the U.S., head of Military Cyber Command Keith B. Alexander stated that cyberattacks on facilities classified as critical infrastructure in the United States have increased 17-fold since 2009.

\section{Cyber warfare}

Cyber warfare involves nation-states using information technology to penetrate another nation's networks to cause damage or disruption. In the US and many other nation-states, cyber warfare has been acknowledged as the fifth domain of warfare (following land, sea, air, and space). Cyber warfare attacks are primarily executed by hackers who are well-trained in exploiting the intricacies of computer networks and operate under the auspices and support of the nation-states. Rather than "shutting down" a target's key networks, a cyber warfare attack may intrude networks for the purpose of compromising valuable data, degrading communications, impairing infrastructural services such as transportation and medical services, or interrupting commerce. For example, in the 2008 South Ossetia war, Russia's initial attacks on Georgian soil were preceded by a synchronized cyberattack that crippled Georgian government websites.

\section{Cyber espionage}

Cyber espionage is the practice of using information technology to obtain secret information without permission from its owners or holders. Cyber espionage is most often used to gain strategic, economic, political, or military advantage. It is conducted through the use of cracking techniques and malware. In the US, the Office of the National Counter Intelligence Executive released a report in 2011 officially acknowledging the legitimate threat of cyber espionage and its potential to damage the United States' strategic economic advantage. In a subsequent opinion piece in the Wall Street Journal, former Director of Homeland Security Michael Chertoff elaborated on the economic impact of China's cyber espionage of intellectual property, which he likens to the "source code" of today's advanced economies. Through the utilization of its massive and inexpensive workforce, China has cheaply and efficiently driven a number of these ideas directly into production. As the fruits of costly investments in research and development from the hosting nation-states, the theft of these innovations is an immense strategic and economic loss to the targets.

With cyberthreats in a state of rapid and continuous evolution, keeping pace in cybersecurity strategy and operations is a major challenge to governments. Cybersecurity is a serious concern to private enterprises as well, given the threat to intellectual property and privately-held critical infrastructure. Advisory organiza- 
tions such as the National Institute of Standards and Technology (NIST) and the International Organization for Standardization (ISO) have recently updated guidelines to promote a more proactive and adaptive approach that prescribes continuous monitoring and real-time assessments.

\section{Improving technology utilization in electronic government around the world}

Few developments have had broader consequences for the public sector than the introduction of the Internet and digital technology. Electronic government offers the promise of utilizing technology to improve public sector performance as well as employing new advances for democracy itself. In its boldest formulation, technology is a tool for long-term system transformation. Unlike traditional bricks and mortar agencies, digital delivery systems are non-hierarchical, non-linear, interactive, and available 24 hours a day, seven days a week. The non-hierarchical character of Internet delivery permits people to look for information at their own convenience. The interactive aspects of e-government allow both citizens and bureaucrats to send as well as receive information.

Given the fundamental nature of these advantages, some predict the Internet will transform government. Many have welcomed electronic governance to improve service delivery and responsiveness to citizens. "Electronic government will not only break down boundaries and reduce transaction costs between citizens and their governments but between levels of government as well," states Stephen Goldsmith, President George W. Bush's former Special Advisor for Faith-Based and Community Initiatives. Jeffrey Seifert and Matthew Bonham argue digital government has the potential to transform governmental efficiency, transparency, citizen trust and political participation in transitional democracies.

Many governmental units have embraced the digital revolution and are putting a wide range of materials from publications, databases to actual government services-online for citizen use. Governments around the world have created websites that facilitate tourism, citizen complaints and business investment. Tourists can book hotels through the government websites of many Caribbean and Pacific island countries. In Australia, citizens can register government complaints through agency websites. Nations such as Bulgaria, the Netherlands and the Czech Republic are attracting overseas investors through their websites.

Despite the great promise of technological advancement, public sector innovation has tended to be smallscale and gradual. Factors such as institutional arrangements, budget scarcity, group conflict, cultural norms and prevailing patterns of social and political behavior have restricted government actions. Because governments are divided into competing agencies and jurisdictions, policymakers struggle to get bureaucrats to work together in promoting technological innovation. Budget considerations prevent government offices from placing services online and using technology for democratic outreach. Cultural norms and patterns of individual behavior affect the manner in which technology is used by citizens and policymakers. In addition, the political process is characterized by intense group conflict over resources. With open and permeable systems, groups organize easily and make demands on the political system.

Governments need to utilize more features that enhance public accountability. Website search engines, for example, are simple but important tools that allow citizens to find the information they want on a site. Currently, only one-third of government websites are searchable, limiting ordinary citizens from finding the information relevant to them. The same logic applies to the technologies that allow citizens to post comments or otherwise provide feedback about a government agency. Citizens bring diverse perspectives and experiences to e-government, and agencies benefit from citizen suggestions, complaints and feedback. A simple feature such as a comment form empowers citizens by giving them an opportunity to voice their opinion about government services they would like to see.

Countries need to update their sites on a regular basis. Some sites appear to have not been updated in several years, and consequently contain inaccurate information, broken links, and incorrect email contact information. By maintaining their sites and placing more materials online, countries would be encouraging citizens and members of the business community to go online and use e-government resources.

\section{Conclusion}

The development of e-government is an evolutionary process, while leaders will ensure that it continually improving services through internal processes and efficient response to external demands. Hence, wider choices in accessing government services with more open and transparent government decision making. The e-government's role is not only to have qualified e-employees. It is, rather, required to change the whole 
society and to train people on how to use e-services and how to deal with the related technologies. Given the diversity of players involved in delivering government services, effective e-government often requires coalitions of partners both within government and between government and the private and non-profit sectors. The resulting organizational, legal, and technological relationships are complex and difficult to manage, yet they offer a way to harness resources that government cannot mount on its own. These partnerships may also be a way to deal with the chronic shortage of IT professionals interested in government careers.

Like any new technology project, electronic government is difficult, but it's made even more difficult because it places so much pressure on the entire enterprise. The e-government vision is a vision of integrated information and services. This means radical changes are needed in what happens behind the Web site that citizens see. New business processes, different information flows, changed policies, new kinds of records, advanced security measures, and new data management methods are all part of the integration story. This deeply transformational work is why leadership is so critical.

\section{References}

1. Darrell M. West (2008). Improving Technology Utilization in Electronic Government around the World. Available at https://www.brookings.edu/research/improving-technology-utilization-in-electronicgovernment-around-the-world-2008/.

2. Edward R. Griffor, Christopher Greer, David A. Wollman, Martin J. Burns (2017). Framework for Cyber-Physical Systems: Volume 2. Working Group Reports. Available at https://www.nist.gov/publications/framework-cyber-physical-systems-volume-2-working-group-reports.

3. Jean Hartley and Maria Allison (2000). The Role of Leadership in the Modernization and Improvement of Public Services. Public Money and Management, 20(2), 35-40. DOI: 10.1111/1467-9302.00209.

4. Jim Norris, Pradyumna Siddhartha, Bret Taylor, Jake Whitehill (2001). Xinru WooThe Impact of the Internet on Developing Countries. Available at http://cs.stanford.edu/people/eroberts/cs201/projects/third-world/index.html.

5. Rajendra Kumar \& Michael L. Best (2007). Impact and Sustainability of E-Government Services in Developing Countries: Lessons Learned from Tamil Nadu, India. The Information Society, 22(1), 1-12. Available at http://www.tandfonline.com/doi/abs/10.1080/01972240500388149.

6. Tan Wee Kwang (2016). E-government global trends: Integrated services, open data, e-participation and digital technologies Enterprise innovation. Available at http://www.enterpriseinnovation.net/article/egovernment-global-trends-integrated-services-open-data-e-participation-and-digital.

7. The United Nations E-Government Survey 2016 (July 2016). Available at https://publicadministration.un.org/egovkb/en-us/Reports/UN-E-Government-Survey-2016.

8. Tim Maurer, Michael Chertoff (2017). Economic Cybersecurity .The Carnegie Podcast. Available at http://carnegieendowment.org/2017/07/14/michael-chertoff-and-tim-maurer-on-economic-cyber-securitypub-71551.

9. What is Cyber Security? Available at https://www.paloaltonetworks.com/cyberpedia/what-is-cybersecurity. 